\title{
The potential biological mechanisms of obesity effects on depression: A systematic review of the literature and knowledge mining
}

\author{
Yanhong Gong ${ }^{1,2 *}$, Dafang Wang ${ }^{3}$, Xiulan Zhang ${ }^{1}$, Zhiyong Qu ${ }^{1}$, Pozi Liu ${ }^{4}$, Hong Zou ${ }^{2}$ \\ ${ }^{1}$ School of Social Development and Public Policy, Beijing Normal University, Beijing, China; \\ *Corresponding Author: yhgong2316@sina.com \\ ${ }^{2}$ School of Psychology, Beijing Normal University, Beijing, China \\ ${ }^{3}$ Department of Paediatrics, Yuquan Hospital, Tsinghua University, Beijing, China \\ ${ }^{4}$ Department of Mental Health, Yuquan Hospital, Tsinghua University, Beijing, China \\ Received 26 August 2013; revised 26 September 2013; accepted 16 October 2013 \\ Copyright (c) 2013 Yanhong Gong et al. This is an open access article distributed under the Creative Commons Attribution License, \\ which permits unrestricted use, distribution, and reproduction in any medium, provided the original work is properly cited.
}

\begin{abstract}
Depression and obesity (BMI $\geq 30$ ) have been recognized as major public health issues worldwide. Although they have traditionally been compartmentalized as separate physical and emotional health conditions, evidence has suggested interactions and common pathways between them, implying that they probably shared common underlying biological mechanisms. By a systematic review of the literature and knowledge mining, we explore a potential biological mechanism of obesity effects on depression. Bioactivators in the body of obesity including adiponectin, leptin and its receptors, ghrelin, endocannabinoids and orexin receptors may contribute to depression by the hypothalamic pituitary adrenal axis, psycho-neuro-immunological system, neurovegetative system and brain areas control of mood and emotion such as hippocampus, cortex and amygdala.
\end{abstract}

Keywords: Obesity; Depression; Biological Mechanisms; Literature and Knowledge Mining

\section{INTRODUCTION}

Obesity is an increasingly prevalent public-health problem with significant costs in the form of disease and premature death [1], increased health-care costs [2], and social stigmatization [3]. In addition, obesity causes or exacerbates many health conditions, both independently and in association with other diseases [1]. Recent data from the National Physical Fitness Monitoring in China in 2010 indicate that approximately $32.1 \%$ of adults and $39.8 \%$ of oldster Chinese are obese. Physical complications from obesity have been studied extensively, especially coronary heart disease, certain forms of cancer, and type 2 diabetes [4]. However, less is known about the relationship between obesity and major depressive disorder.

For the most part, obesity and depression have been compartmentalized as separate health problems of a physical and emotional nature, respectively [5]. However, the fact that depression and obesity have shared symptoms such as sleep problems, sedentary behavior and dysregulated food intake is not a mere coincidence but appears to be related to shared pathophysiological mechanisms. The purpose of the present article is to review the physiological and biochemical changes induced by depression and obesity in the body, highlight similarities in their biological presentation, review and speculate common pathways or other connecting mechanisms.

\section{METHODS}

Amounts of Medline, PsycINFO, PubMed, and Web of Science searches were conducted using the key words metabolic syndrom, waist circumference, waist hip ratio, obesity, overweight, central adiposity/obesity, visceral adiposity/obesity, body fat distribution, psychological, depression/major depressive disorder. After a systematic review of the literature, the method of noninteractive literature-based knowledge discovery created by D. R. Swanson was used to search the relative literature between obesity and depression by a man-computer interactive system named as Arrowsmith. The process starts with a given $\mathrm{A}$ and $\mathrm{C}$. It tretrieves all literature containing either 
A or C. From this, a list of B-terms is extracted. These B-terms are words orphrases (of up to six words) which co-occur at least twice with both $\mathrm{A}$ and $\mathrm{C}$. The stop list is applied next and the list is further edited by the user to remove redundancies and useless terms. Finally, the system display seach A-B-C link with the titles in which the $\mathrm{A}-\mathrm{B}$ and B-C co-occurrences are present. The user can now study the context of the co-occurrences and determine which A-C links merit further investigation.

\section{RESULTS}

Although it seems obvious that obese people would likely be at higher risk for major depressive disorder (MDD) problems, the mediating factors in the relationship between psychological problems and obesity are still not well established. In this section, we review the internal biological activities of the body that may serve as links between obesity and depression and possible targets for both disorders.

\subsection{Adiponectin}

Adiponectin (also referred to as GBP-28, apM1, AdipoQ and Acrp 30) is a protein which in humans is encoded by the ADIPOQ gene [6]. It is involved in regulating glucose levels as well as fatty acid breakdown, and a protein hormone that modulates a number of metabolic processes, including glucose regulation and fatty acid catabolism [7]. Adiponectin is exclusively secreted from adipose tissue and also from the placenta in pregnancy into the bloodstream and is very abundant in plasma relative to many hormones [8]. Levels of the hormone are inversely correlated with body fat percentage in adults. The hormone plays a role in the suppression of the metabolic derangements that may result in type 2 diabetes [9], obesity, atherosclerosis [7], non-alcoholic fatty liver disease (NAFLD) and an independent risk factor for metabolic syndrome [8].

A epidemiological studies documenting an association between decreased plasma adiponectin concentration and an increased risk of MDD were published [10]. And the adiponectin hypothesis about psychopathology in the context of obesity was proposed [11]. Moreover, circulating adiponectin levels have also been shown to correlate inversely with anxiety scores, a condition highly comorbid with depression [12].

As an adipokines, adiponectin has been believed to play a role in developing of depression. Adiponectin levels in plasma are reduced in a chronic social-defeat stress model of depression, which correlates with decreased social interaction time and intracerebroventricular (i.c.v.) injection of an adiponectin neutralizing antibody precipitates stress-induced depressive-like behavior. Conversely, i.c.v. administration of exogenous adiponectin produces antidepressant-like behavioral effects in normal-weight mice and in diet-induced obese diabetic mice [13]. Results of studies examining adiponectin in clinical populations have been variable. The original work about the links reported a decrease in plasma adiponectin concentrations in symptomatic patients with MDD [10] and an increase in adiponectin in patients with depression that was successfully treated [14], other studies have been unable to find changes in people with depression [15-17]. This effect may be mediated by antidepressants in the short-term [18] and weight gain over time [19], but recent work suggests that the presence of weight gain and depression also appears to be additive. The two conditions appear to have a greater effect on adiponectin that either does separately, indicating that an underlying vulnerability may be conferred and then compounded by either of the two conditions and their resultant hypoadiponectinemia. Moreover, circulating adiponectin levels have been shown to correlate inversely with anxiety scores by the pathway of Psycho-neuro-immunological aspects [12].

Adiponectin may regulate the expression of several pro- and antiinflammatory cytokines and reduce both secretion and attenuate the biological effects of TNF-a $[20,21]$ and to induce the production of antiinflammatory cytokines such as interleukin-10 (IL-10) and interleukin-1 receptor antagonist (IL-1RA) [22]. Proinflammatory mediators such as IL-6 can regulate the expression of adiponectin by way of suppressing adiponectin transcription and translation [23], and contrarily, weight loss is a potent inducer of adiponectin synthesis d which might lead to dysregulation of the controls that inhibit the production of proinflammatory cytokines, thereby leading to the production of increased levels of proinflammatory mediators [24]. The hypothalamic pituitary adrenal (HPA) axis also plays a role in adiponectin regulation; adiponectin gene expression is reversibly downregulated by dexamethasone [23], and glucocorticoids have been shown to inhibit adiponectin function [25].

\subsection{Leptin and Its Receptors}

Leptin is a peptide hormone secreted from adipocytes, circulates in the blood as a $16-\mathrm{kDa}$ protein and enters the brain by a saturable transport mechanism. Leptin has been well-recognized as an adiposity negative feedback signal and a critical mediator of energy homeostasis since its discovery. Leptin receptor is a single membrane-spanning protein that belongs to the class I cytokine receptor superfamily. Accumulating evidence has expanded the function of leptin from the control of energy balance to the regulation of other physiological processes such as reproduction and cognition [26,27]. Supporting this notion, the leptin receptor is widely distributed in discrete brain regions. Particularly, LepRb, an 
isoforms of the leptin receptor, is highly expressed in brain areas implicated in the control of mood and emotion such as the hippocampus, cortex and amygdala.

Animal models of depression in rats or mice exposed to chronic unpredictable stress or chronic social defeat stress to develop behavioral deficits and endocrine abnormalities, mimicking the symptoms of human depression, showed decreased basal levels of leptin in plasma [28]. It was hypothesized that leptin insufficiency may underlie depression-like behavioral deficits [29]. One of the depression-like behaviors in chronically stressed animals is reduction of sucrose preference, which is regarded as an analog of anhedonia, a key symptom of depression in human [30]. Systemic administration of leptin can reverse the chronic stress-induced decrease in sucrose preference [28].

Studies about the role of leptin signaling in human depression is limited and controversial [31,32]. With larger sample sizes, researchers demonstrated that plasma leptin levels were decreased in patients with major depression independent of body mass status [33,34]. Also, lower levels of leptin in cerebrospinal fluid were found in suicide attempters with depression than those without depression [35,36]. These suggest a link between reduced leptin levels and major depression. It has been reported that obese people are approximately $20 \%$ more likely to have depressive disorders than non-obese subjects [37], and leptin resistance is caused by defects in the leptin signaling pathway possibly at several levels, including impaired transport of leptin across the blood-brain-barrier, reduced function of the leptin receptor and defects in leptin signal transduction [38].

The principal homeostatic site of action of leptin and ghrelin is the hypothalamic arcuate nucleus, where they exert anorexigenic or orexigenic effects, respectively, through a biologically elegant system of neuropeptides. Interestingly, receptors for leptin and ghrelin, as well as receptors for other feeding peptides are expressed in several depression-related limbic substrates [39]. In light of leptin's ability to inhibit depressive behaviors inanimal models, it is possible that leptin resistance may contribute to the higher rate for depression in obese people. This could also help to interpret some of the conflicting results obtained in relation to circulating leptin levels in depressed patients [40].

\subsection{Ghrelin}

Ghrelin is a natural ligand for the growth hormone (GH)-secretagogue receptor (GHS-R), is primarily produced in the stomach. Ghrelin plays a critical role in a variety of physiological processes, including the stimulation of GH secretion and regulation of energy homeostasis by stimulating food intake and promoting adiposity via a GH-independent mechanism [41,42].
Prior studies found that rises in ghrelin occur not only in response to states of energy insufficiency [43-45] but also following Anxiety and depression [46], and elevations in either gastric ghrelin mRNA or total plasma ghrelin have been observed in response to various models of acute stress, including following a tail pinch stress protocol in ddy mice and following a water avoidance stress protocol in Wistar Kyoto and Sprague-Dawley rat $[47,48]$.

Mouse models has revealed that increasing circulating ghrelin levels by 10 days of calorie restriction or by acute s.c. injection produces antidepressant-like responses in the forced swim test, but caloric restriction no longer induced these responses in mice lacking ghrelin receptors (GHSRnull mice), thus suggesting that interference with ghrelin signaling negates the antidepressant-like behaviors associated with calorie restriction [46]. Also, upon challenge with the chronic social defeat stress (CSDS) protocol, GHSR-null mice manifested greater social isolation (another marker of depressivelike behavior) than did wild-type littermates. Thus, it has been suggested that activation of ghrelin signaling pathways in response to chronic stress may be a homeostatic adaptation that helps individuals cope with stress.

Studies has demonstrated the hippocampus as being involved in antidepressant efficacy and other aspects of depression, including that associated with stress, and the hippocampus together with the neocortex mediates cognitive aspects of depression such as memory impairment and feelings of worthlessness, hopelessness, guilt, and suicidality [49]. Interestingly, GHSRs are known to be expressed within all regions of the hippocampus [50,51]. In addition, peripherally administered ghrelin is taken up by and increases spine synapse density within the hippocampus [52]. Ghrelin also recently has been shown to stimulate cellular proliferation and differentiation of adult rat hippocampal progenitor cells [53,54], thus suggesting that ghrelin also might induce hippocampal neurogenesis.

\subsection{Endocannabinoids}

Endocannabinoids are lipid mediators derived from membrane phospholipids or triglycerides with complex effects on body weight and metabolic regulation [55,56]. Endocannabinoids in tissues controlling energy homeostasis are altered in obesity, and has been suspected to contribute to the association of visceral fat accumulation with metabolic diseases. The endocannabinoid system, which exists in both the brain and the periphery, is both a regulator and effector of the stress response [57,58]. Preclinical studies have demonstrated that the contents of the endocannabinoids in limbic and hindbrain regions are regulated by a variety of stressful stimuli [57]. These 
changes in endocannabinoid activity dampen or promote recovery of the hormonal stress response since endocannabinoid signaling negatively modulates the sensitivity and output of the hypothalamic-pituitary-adrenal (HPA) axis [57,58].

Prior study demonstrated that exposure of humans to an acute social stressor results in altered circulating concentrations of the endocannabinoids [59,60], the source of circulating endocannabinoids is not well characterized, but adipocytes, endothelial cells and macrophages, as well as visceral organs, such as the liver and intestines, all possess the ability to synthesize and release endocannabinoids into the blood [61-63]. Previous findings of a reduction in circulating endocannabinoid content in an independent population diagnosed with major depression werereplicated [62].

Endocannabinoid signaling is known to influence mood and emotion, such that impairments in endocannabinoid signaling can produce depressive-like and anxiety-like symptoms in rodents [60] and administration of CB1 receptor (G-protein coupled receptors) antagonists to humans has been found to increase indices of depression and anxiety [63]. Accordingly, the deficit in circulating endocannabinoids documented in individuals with major depression may contribute to the emotional sequelae associated with this disease.

\subsection{Orexin Receptors}

Orexin-A and orexin-B, via their receptors orexin-1 receptor $(\mathrm{OX} 1 \mathrm{R})$ and orexin-2 receptor (OX2R) have been shown to play a role in the regulation of feeding, body weight, and energy expenditure. The orexigenic peptides, orexin-A and orexin-B, are proteolytically cleaved from a common precursor, prepro-orexin and share $46 \%$ amino acid sequence identity [64,65]. The neurons producing orexins are located in the lateral and posterior hypothalamus and send their projections widely into the central nervous system, resulting in multiple physiological functions, including the control of arousal and sleepwake cycle, regulation of cardiovascular and autonomic function, and the neuroendocrine system [66-68]. Orexins bind to and activate two G-protein-coupled receptors, orexin-1 receptor (OX1R) and orexin-2 receptor (OX2R), which display 64\% amino acid sequence identity [67]. Orexin-A binds with a high affinity to OX1R, whilst OX2R binds both orexin-A and orexin-B with similar affinity. Studies have demonstrated that the orexin receptors distributes in human isolated adipocytes [69] and non-central tissue distribution include the adrenal gland [70], male reproductive system [71] thyroid, lung, kidney, and jejunum [72].

Calorie restriction and subsequent weight loss in mammals induces a wide array of behavioral responses directed toward promoting the identification of new food sources. These responses have been well studied in mice and include increased arousal, increased locomotor activity, and decreased anxiety-like behavior [73-75]. Interestingly, several psychiatric disorders, notably "typical” major depressive disorder and anorexia nervosa, are characterized by reduced calorie intake. Behavioral responses to calorie restriction are thought to mediate certain clinical aspects of the illness. For example, reduced production of leptin by adipose tissue has been implicated in the increased psychomotor activity of patients suffering from anorexia nervosa [76].

Findings demonstrated significant downregulation of prepro-orexin mRNA expression after chronic social defeat stress. Interestingly, decreased levels of orexin-A were reported in the CSF of suicidal patients with major depressive disorder [77], supporting chronic social defeat stress as a model of major depression. One interesting possibility is that prolonged reduction in orexin signaling may contribute to the development of neurovegetative symptoms seen in major depression. Orexin neurons have broad projections, and multiple functions have been attributed to orexin signaling, including consolidation of arousal, regulation of metabolism, food intake, and cardiovascular responses, controlling fluid intake, and mediating food and drug reward responses [78-81]. Given the multiple roles of orexin neurons, reduction in orexin signaling makes an attractive candidate to explain the disrupted sleep/wake cycles, altered appetite, and psychomotor retardation often observed in depressed patients.

\section{DISCUSSION}

The complex relationship between obesity and depression had been reported based on only one bioactivator in most of prior studies. This review as well as knowledge mining discusses a potential biological mechanism of obesity effects on depression systemly. Bioactivators in the body of obesity including adiponectin, leptin and its receptors, ghrelin, endocannabinoids and orexin receptors may contribute to depression by the hypothalamic pituitary adrenal axis, psycho-neuro-immunological system, neurovegetative system and brain areas control of mood and emotion such as hippocampus, cortex and amygdala.

Adiponectin plays a role in the suppression of the metabolic derangements and the levels of which are inversely correlated with body fat percentage and anxiety scores. The biological mechanism may be that obesity results in the decrease of plasma adiponectin concerntration and then increases the risk of MDD by HPA axis and psycho-neuro-immunological system. As an adiposity negative feedback, leptin is a critical mediator of energy homeostasis. The decreased plasma leptin level will contribute to depressive behaviors through a biological 
system of neuropeptides. The rises in ghrelin occur following depression, and the points of action may be regions of hippocampus. Endocannabinoid is an important mediator of energy homeostasis and a regulator and effector of the stress response. The biological mechanism may be that depression leads to the rise of endocannabinoids, then make the fat accumulation and subsequent to come into be obesity. Orexin produced by neurons is located in hypothalamus. Weight loss will induce a behavioral response of food intake and this response will decrease anxiety-like behavior through the neurovegetative system.

The method of noninteractive literature-based knowledge discovery contributes to exploring the relation between psychological characteristics and illness, and the theoretical hypothesis of biological mechanism can be constructed between them through a system literature review to provide valuable reference for medical and psylogical researchers to benefit mental diseases understanding and disease prevention and control.

\section{ACKNOWLEDGEMENTS}

We would like to thank D. F. Wang for collecting the full text of part of literatures, S. J. Wang for proofreading the manuscript and the unknown reviewers for their important and helpful comments.

\section{REFERENCES}

[1] Smith, M.M. and Minson, C.T. (2012) Obesity and adipokines: Effects on sympathetic overactivity. Journal of Physiology, 590, 1787-1801.

[2] Finkelstein, E.A., Trogdon, J.G. and Cohen, J.W. (2009) Annual medical spending attributable to obesity: Payerand service-specific estimates. Health Affairs, 28, 822831. http://dx.doi.org/10.1377/hlthaff.28.5.w822

[3] Dixon, J.B. (2009) The effect of obesity on health outcomes. Molecular and Cellular Endocrinology, 316, 104108. http://dx.doi.org/10.1016/j.mce.2009.07.008

[4] Hotta, K., Funahashi, T., Arita, Y., Takahashi, M., et al. (2000) Plasma concentrations of a novel, adipose-specific protein, adiponectin, in type 2 diabetic patients. Arteriosclerosis, Thrombosis, and Vascular Biology, 20, 15951599. http://dx.doi.org/10.1161/01.ATV.20.6.1595

[5] Faith, M.S., Matz, P.E. and Jorge, M.A. (2002) Obesitydepression associations in the population. Journal of Psychosomatic Research, 53, 935-942. http://dx.doi.org/10.1016/S0022-3999(02)00308-2

[6] Maeda, K., Okubo, K., Shimomura, I., Funahashi, T., Matsuzawa, Y. and Matsubara, K. (1996) cDNA cloning and expression of a novel adipose specific collagen-like factor, apM1 (adipose most abundant gene transcript 1). Biochemical and Biophysical Research Communications, 221, 286-289. http://dx.doi.org/10.1006/bbrc.1996.0587

[7] Díez, J.J. and Iglesias, P. (2003) The role of the novel adipocyte-derived hormone adiponectin in human disease.
European Journal of Endocrinology, 148, 293-300. http://dx.doi.org/10.1530/eje.0.1480293

[8] Chen, J. (2006) Secretion of adiponectin by human placenta: Differential modulation of adiponectin and its receptors by cytokines. Diabetalogica, 49, 1292-1302. http://dx.doi.org/10.1007/s00125-006-0194-7

[9] Renaldi, O., Pramono, B., Sinorita, H., Purnomo, L.B., Asdie, R.H. and Asdie, A.H. (2009) Hypoadiponectinemia: A risk factor for metabolic syndrome. Acta Medica Indonesiana, 134, 414-416.

[10] Ukkola, O. and Santaniemi, M. (2002) Adiponectin: A link between excess adiposity and associated comorbidities? Journal of Molecular Medicine, 80, 696-702. http://dx.doi.org/10.1007/s00109-002-0378-7

[11] Leo, R., Di Lorenzo, G. and Tesauro, M. (2006) Decreased plasma adiponectin concentration in major depression. Neuroscience Letters, 407, 211-213. http://dx.doi.org/10.1016/j.neulet.2006.08.043

[12] Yilmaz, Y. (2008) Psychopathology in the context of obesity: The adiponectin hypothesis. Medical Hypotheses, 70, 902-903.

http://dx.doi.org/10.1016/j.mehy.2007.08.019

[13] Nagata, T. and Yamada, H. (2006) Psycho-neuro-immunological aspects of eating disorders. International Congress Series, 1287, 279-284. http://dx.doi.org/10.1016/j.ics.2005.11.097

[14] Narita, K., Murata, T., Takahashi, T., Kosaka, H., Omata, N. and Wada, Y. (2006) Plasma levels of adiponectin and tumor necrosis factor-alpha in patients with remitted major depression receiving long-term maintenance antidepressant therapy. Progress in Neuro-Psychopharmacology and Biological Psychiatry, 30, 1159-1162.

http://dx.doi.org/10.1016/j.pnpbp.2006.03.030

[15] Weber-Hamann, B., Kratzsch, J. and Kopf, D. (2007) Resistin and a diponectin in major depression: The association with free cortisol and effects of antidepressant treatment. Journal of Psychiatric Research, 41, 344-350. http://dx.doi.org/10.1016/j.jpsychires.2006.01.002

[16] Mamalakis, G., Kiriakakis, M. and Tsibinos, G. (2006) Depression and serum adiponectin and adipose omega-3 and omega-6 fatty acids in adolescents. Pharmacology Biochemistry and Behavior, 85, 474-479. http://dx.doi.org/10.1016/j.pbb.2006.10.008

[17] Pan, A., Ye, X., Franco, O.H., Li, H., Yu, Z., Wang, J., Qi, Q., Gu, W., Pang, X., Liu, H. and Lin, X. (2008) The association of depressive symptoms with inflammatory factors and adipokines in middle-aged and older Chinese. PLOS ONE, 3, 1392. http://dx.doi.org/10.1371/journal.pone.0001392

[18] Chen, Y.C., Lin, W.W., Chen, Y.J., Mao, W.C., Hung, Y.J. (2010) Antidepressant effects on insulin sensitivity and proinflammatory cytokines in the depressed males. Mediators of Inflammation, Article ID: 573594. http://dx.doi.org/10.1155/2010/573594

[19] You, T., Nicklas, B.J. and Ding, J. (2008) The metabolic syndrome is associated with circulating adipokines in older adults across a wide range of adiposity. Journal of Gerontology, Series A, 63, 414-419.

http://dx.doi.org/10.1093/gerona/63.4.414 
[20] Fernandez-Real, J.M., Lopez-Bermejo, A. and Casamitjana, R. (2003) Novel interactions of adiponectin with the endocrine system and inflammatory parameters. The Journal of Clinical Endocrinology \& Metabolism, 88, 27142718. http://dx.doi.org/10.1210/jc.2002-021583

[21] Aldhahi, W. and Hamdy, O. (2003) Adipokines, inflamemation, and the endothelium in diabetes. Current Diabetes Reports, 3, 293-298. http://dx.doi.org/10.1007/s11892-003-0020-2

[22] Tilg, H. and Wolf, A.M. (2005) Adiponectin:a key fatderived molecule regulating inflammation. Expert Opinion on Biological Therapy, 9, 245-251. http://dx.doi.org/10.1517/14728222.9.2.245

[23] Fasshauer, M., Klein, J., Neumann, S., Eszlinger, M. and Paschke, R. (2002) Hormonal regulation of adiponectin gene expression in 3T3-L1 adipocytes. Biochemical and Biophysical Research Communications, 290, 1084-1089. http://dx.doi.org/10.1006/bbrc.2001.6307

[24] Bruun, J.M., Lihn, A.S. and Verdich, C. (2003) Regulation of adiponectin by adipose tissue-derived cytokines: In vivo and in vitro investigations in humans. American Journal of Physiology, 285, 527-533.

[25] Fallo, F., Scarda, A. and Sonino, N. (2004) Effect of glucocorticoids on adiponectin: A study in healthy subjects and in Cushing's syndrome. European Journal of Endocrinology, 150, 339-344. http://dx.doi.org/10.1530/eje.0.1500339

[26] Chehab, F.F. (2000) Leptin as a regulator of adipose mass and reproduction. Trends in Pharmacological Sciences, 21, 309-314. http://dx.doi.org/10.1016/S0165-6147(00)01514-5

[27] Farr, S.A., Banks, W.A. and Morley, J.E. (2006) Effects of leptin on memory processing. Peptides, 27, 1420-1425. http://dx.doi.org/10.1016/j.peptides.2005.10.006

[28] Lu, X.Y., Kim, C.S., Frazer, A. and Zhang, W. (2006) Leptin: A potential novel antidepressant. Proceedings of the National Academy of Sciences of the USA, 103, 15931598. http://dx.doi.org/10.1073/pnas.0508901103

[29] Willner, P. (2005) Chronic mild stress (CMS) revisited: Consistency and behavioural-neurobiological concordance in the effects of CMS. Neuropsychobiology, 52, 90-110. http://dx.doi.org/10.1159/000087097

[30] Katz, R.J. (1982) Animal model of depression: Pharmacological sensitivity of a hedonic deficit. Pharmacology Biochemistry and Behavior, 16, 965-968. http://dx.doi.org/10.1016/0091-3057(82)90053-3

[31] Antonijevic, I.A., Murck, H., Frieboes, R.M., Horn, R., Brabant, G. and Steiger, A. (1998) Elevated nocturnal profiles of serum leptin in patients with depression. Journal of Psychiatric Research, 32, 403-410. http://dx.doi.org/10.1016/S0022-3956(98)00032-6

[32] Rubin, R.T., Rhodes, M.E. and Czambel, R.K. (2002) Sexual diergism of baseline plasma leptin and leptin suppression by arginine vasopressin in major depressives and matched controls. Psychiatry Research, 113, 255-268. http://dx.doi.org/10.1016/S0165-1781(02)00263-9

[33] Jow, G.M., Yang, T.T. and Chen, C.L. (2006) Leptin and cholesterol levels are low in major depressive disorder, but high in schizophrenia. Journal of Affective Disorders, 90, 21-27. http://dx.doi.org/10.1016/j.jad.2005.09.015

[34] Kraus, T., Haack, M., Schuld, A., Hinze-Selch, D. and Pollmacher, T. (2001) Low leptin levels but normal body mass indices in patients with depression or schizophrenia. Neuroendocrinology, 73, 243-247.

http://dx.doi.org/10.1159/000054641

[35] Atmaca, M., Kuloglu, M., Tezcan, E., Ustundag, B., Gecici, O. and Firidin, B. (2002) Serum leptin and cholesterol values in suicide attempters. Neuropsychobiology, 45, 124-127. http://dx.doi.org/10.1159/000054950

[36] Westling, S., Ahren, B., Traskman-Bendz, L. and Westrin, A. (2004) Low CSF leptin in female suicide attempters with major depression. Journal of Affective Disorders, 81, 41-48. http://dx.doi.org/10.1016/j.jad.2003.07.002

[37] Simon, G.E., Von Korff, M., Saunders, K., et al. (2006) Association between obesity and psychiatric disorders in the US adult population. Archives of General Psychiatry, 63, 824-830. http://dx.doi.org/10.1001/archpsyc.63.7.824

[38] Munzberg, H. and Myers, M.G. (2005) Molecular and anatomical determinants of central leptin resistance. $\mathrm{Na}$ ture Neuroscience, 8, 566-570. http://dx.doi.org/10.1038/nn1454

[39] Vaishnav, K. and Eric, J.N. (2010) Linking molecules to mood: New insight into the biology of depression. American Journal of Psychiatry, 167, 1305-1320. http://dx.doi.org/10.1176/appi.ajp.2009.10030434

[40] Lu, X.-Y. (2007) The leptin hypothesis of depression: A potential link between mood disorders and obesity? Current Opinion in Pharmacology, 7, 648-652. http://dx.doi.org/10.1016/j.coph.2007.10.010

[41] Korbonits, M., Goldstone, A.P., Gueorguiev, M. and Grossman, A.B. (2004) Ghrelin-A hormone with multiple functions. Frontiers in Neuroendocrinology, 25, 27-68. http://dx.doi.org/10.1016/j.yfrne.2004.03.002

[42] Kojima, M. and Kangawa, K. (2005) Ghrelin: Structure and function. Physiological Reviews, 85, 495-522. http://dx.doi.org/10.1152/physrev.00012.2004

[43] Otto, B., Cuntz, U. and Fruehauf, E. (2001) Weight gain decreases elevated plasma ghrelin concentrations of patients with anorexia nervosa. European Journal of Endocrinology, 145, 669-673.

[44] Cummings, D.E., Weigle, D.S. and Frayo, R.S. (2002) Plasma ghrelin levels after diet-induced weight loss or gastric bypass surgery. New England Journal of Medicine, 346, 1623-1630. http://dx.doi.org/10.1056/NEJMoa012908

[45] Leidy, H., Dougherty, K.A., Frye, B.R., Duke, K.M. and Williams, N.I. (2007) Twenty-four-hour ghrelin is elevated after calorie restriction and exercise training in non-obese women. Obesity, 15, 446-455.

http://dx.doi.org/10.1038/oby.2007.542

[46] Lutter, M., Sakata, I. and Osborne-Lawrence, S. (2008) The orexigenic hormone ghrelin defends against depressive symptoms of chronic stress. Nature Neuroscience, 11, 752-753. http://dx.doi.org/10.1038/nn.2139

[47] Asakawa, A., Inui, A. and Kaga, T. (2001) A role of ghrelin in neuroendocrine and behavioral responses to stress 
in mice. Neuroendocrinology, 74, 143-147. http://dx.doi.org/10.1159/000054680

[48] Kristenssson, E., Sundqvist, M. and Astin, M. (2006) Acute psychological stress raises plasma ghrelin in the rat. $R e$ gulatory Peptides, 134, 114-117. http://dx.doi.org/10.1016/j.regpep.2006.02.003

[49] Nestler, E.J., Barrot, M., Dileone, R.J., et al. (2002) Neurobiology of depression. Neuron, 34, 13-25. http://dx.doi.org/10.1016/S0896-6273(02)00653-0

[50] Zigman, J.M., Jones, J.E., Lee, C.E., Saper, C.B. and Elmquist, J.K. (2006) Expression of ghrelin receptor mRNA in the rat and the mouse brain. Journal of Comparative Neurology, 494, 528-548. http://dx.doi.org/10.1002/cne.20823

[51] Guan, X.M., Yu, H. and Palyha, O.C. (1997) Distribution of mRNA encoding the growth hormone secretagogue receptor in brain and peripheral tissues. Molecular Brain Research, 48, 23-29. http://dx.doi.org/10.1016/S0169-328X(97)00071-5

[52] Diano, S., Farr, S.A., Benoit, S.C., et al. (2006) Ghrelin controls hippocampal spine synapse density and memory performance. Nature Neuroscience, 9, 381-388. http://dx.doi.org/10.1038/nn1656

[53] Johansson, I., Destefanis, S. and Aberg, N.D. (2008) Proliferative and protective effects of growth hormone secretagogues on adult rat hippocampal progenitor cells. Endocrinology, 149, 2191-2199. http://dx.doi.org/10.1210/en.2007-0733

[54] Moon, M., Kim, S., Hwang, L. and Park, S. (2009) Ghrelin regulates hippocampal neurogenesis in adult mice. Endocrine Journal, 56, 525-531. http://dx.doi.org/10.1507/endocrj.K09E-089

[55] Cota, D., Marsicano, G., Lutz, B., Vicennati, V., Stalla, G.K., Pasquali, R. and Pagotto, U. (2003) Endogenous cannabinoid system as a modulator of food intake. International Journal of Obesity and Related Metabolic Disorders, 27, 289-301.

http://dx.doi.org/10.1038/sj.ijo.0802250

[56] Di Marzo, V. and Matias, I. (2005) Endocannabinoid control of food intake and energy balance. Nature Neuroscience, 8, 585-589. http://dx.doi.org/10.1038/nn1457

[57] Gorzalka, B.B., Hill, M.N. and Hillard, C.J. (2008) Regulation of endocannabinoid signaling by stress: Implications for stress-related affective disorders. Neuroscience \& Biobehavioral Reviews, 32, 1152-1160. http://dx.doi.org/10.1016/j.neubiorev.2008.03.004

[58] Steiner, M.A. and Wotjak, C.T. (2008) Role of the endocannabinoid system in regulation of the hypothalamicpituitaryadrenocortical axis. Progress in Brain Research, 170, 397-432.

http://dx.doi.org/10.1016/S0079-6123(08)00433-0

[59] Matthew, N.H., Gregory, E.M., Erica, J.C., Boris, B.G. and Cecilia, J.H. (2009) Circulating endocannabinoids and n-acyl ethanolamines are differentially regulated in major depression and following exposure to social stress. Psychoneuroendocrinology, 34, 1257-1262. http://dx.doi.org/10.1016/j.psyneuen.2009.03.013

[60] Hill, M.N. and Gorzalka, B.B. (2005) Is there a role for the endocannabinoid system in the etiology and treatment of melancholic depression? Behavioural Pharmacology, 16, 333-352. http://dx.doi.org/10.1097/00008877-200509000-00006

[61] Randall, M.D. (2007) Endocannabinoids and the haematological system. British Journal of Pharmacology, 152, 671-675. http://dx.doi.org/10.1038/sj.bjp.0707420

[62] Matias, I., Bisogno, T. and Di Marzo, V. (2006) Endogenous cannabinoids in the brain and peripheral tissues: Regulation of their levels and control of food intake. International Journal of Obesity, 30, 7-12. http://dx.doi.org/10.1038/sj.ijo.0803271

[63] Hill, M.N., Miller, G.E. and Ho, W.S. (2008) Serum endocannabinoid content is altered in females with depresssive disorders: A preliminary report. Pharmacopsychiatry, 41, 48-53. http://dx.doi.org/10.1055/s-2007-993211

[64] Matias, I., Gonthier, M.P. and Petrosino, S. (2007) Role and regulation of acylethanolamides in energy balance: Focus on adipocytes and beta-cells. British Journal of Pharmacology, 152, 676-690.

http://dx.doi.org/10.1038/sj.bjp.0707424

[65] Christensen, R., Kristensen, P.K. and Bartels, E.M. (2007) Efficacy and safety of the weight-loss drug rimonabant: A meta-analysis of randomised trials. Lancet, 370, 17061713. http://dx.doi.org/10.1016/S0140-6736(07)61721-8

[66] De Lecea, L., Kilduff, T.S. and Peyron, C. (1998) The hypocretins: Hypothalamus-specific peptides with neuroexcitatory activity. PNAS, 95, 322-327.

http://dx.doi.org/10.1073/pnas.95.1.322

[67] Sakurai, T.A.A., Ishii, M. and Matsuzaki, I. (1998) Orexins and orexin receptors: A family of hypothalamic neuropeptides and G-proteincoupled receptors that regulate feeding behaviour. Cell, 92, 573-585. http://dx.doi.org/10.1016/S0092-8674(00)80949-6

[68] Ida, T.N.K., Katayama, T. and Murakami, N. (1999) Effect of lateral cerebroventricular injection of the appetitestimulating neuropeptide, orexin and neuropeptide $\mathrm{Y}$, on the various behavioral activities of rats. Brain Research, 821, 526-529. http://dx.doi.org/10.1016/S0006-8993(99)01131-2

[69] Samson, W.K., Gosnell, B. and Chang, J.K. (1999) Cardiovascular regulatory actions of the hypocretins in brain. Brain Research, 831, 248-253. http://dx.doi.org/10.1016/S0006-8993(99)01457-2

[70] Peyron, C., Faraco, J. and Rogers, W. (2000) A mutation in a case of early onset narcolepsy and a generalized absence of hypocretin peptides in human narcoleptic brains. Nature Medicine, 6, 991-997. http://dx.doi.org/10.1038/79690

[71] Digby, J.E., Chen, J. and Tang, J.Y. (2006) Orexin receptor expression in human adipose tissue: Effects of orexinA and orexin-B. Journal of Endocrinology, 191, 129-136. http://dx.doi.org/10.1677/joe.1.06886

[72] Randeva, H.S., Karteris, E. and Grammatopoulos, D. (2001) Expression of orexin-A and functional orexin type 2 receptors in the humanadult adrenals: Implications for adrenal function and energy homeostasis. The Journal of Clinical Endocrinology \& Metabolism, 86, 4808-4813. http://dx.doi.org/10.1210/jc.86.10.4808

[73] Karteris, E., Machado, R.J. and Chen, J. (2005) Food 
deprivation differentially modulates orexin receptor expression and signaling in rat hypothalamus and adrenal cortex. American Journal of Physiology, 288, 1089-1100.

[74] Johren, O., Neidert, S.J. and Kummer, M. (2001) Preproorexin and orexin receptor mRNAs are differentially expressed in peripheral tissues of male and female rats. Endocrinology, 142, 3324-3331. http://dx.doi.org/10.1210/en.142.8.3324

[75] Marchant, E.G. and Mistlberger, R.E. (1997) Anticipation and entrainment to feeding time in intact and SCN-ablated C57BL/6j mice. Brain Research, 765, 273-282. http://dx.doi.org/10.1016/S0006-8993(97)00571-4

[76] Yamanaka, A., Beuckmann, C.T. and Willie, J.T. (2003) Hypothalamic orexin neurons regulate arousal according to energy balance in mice. Neuron, 38, 701-713. http://dx.doi.org/10.1016/S0896-6273(03)00331-3

[77] Inoue, K., Zorrilla, E.P. and Tabarin, A. (2004) Reduction of anxiety after restricted feeding in the rat: Implication for eating disorders. Biological Psychiatry, 55, 10751081. http://dx.doi.org/10.1016/j.biopsych.2004.01.026
[78] Holtkamp, K., Herpertz-Dahlmann, B., Mika, C., et al. (2003) Elevated physical activity and low leptin levels co-occur in patients with anorexia nervosa. The Journal of Clinical Endocrinology \& Metabolism, 88, 5169-5174. http://dx.doi.org/10.1210/jc.2003-030569

[79] Brundin, L., Bjorkqvist, M. and Petersen, A. (2007) Reduced orexin levels in the cerebrospinal fluid of suicidal patients with major depressive disorder. European Neuropsychopharmacology, 17, 573-579. http://dx.doi.org/10.1016/j.euroneuro.2007.01.005

[80] Harris, G.C., Wimmer, M. and Aston-Jones, G. (2005) A role for lateral hypothalamic orexin neurons in reward seeking. Nature, 437, 556-559. http://dx.doi.org/10.1038/nature04071

[81] Harris, G.C. and Aston-Jones, G. (2006) Arousal and reward: A dichotomy in orexin function. Trends in Neurosciences, 29, 571-577. http://dx.doi.org/10.1016/j.tins.2006.08.002 